\title{
G. Fusco Girard, Mallarmé «Dernière Mode». L'infinito e il nulla
}

\section{Michele Costagliola D'abele}

\section{Q OpenEdition}

1 Journals

\section{Edizione digitale}

URL: https://journals.openedition.org/studifrancesi/3175

DOI: $10.4000 /$ studifrancesi.3175

ISSN: 2421-5856

\section{Editore}

Rosenberg \& Sellier

\section{Edizione cartacea}

Data di pubblicazione: 1 juillet 2013

Paginazione: 480-481

ISSN: 0039-2944

\section{Notizia bibliografica digitale}

Michele Costagliola D'abele, «G. Fusco Girard, Mallarmé «Dernière Mode». L'infinito e il nulla», Studi

Francesi [Online], 170 (LVII | II) | 2013, online dal 30 novembre 2015, consultato il 31 janvier 2023. URL: http://journals.openedition.org/studifrancesi/3175 ; DOI: https://doi.org/10.4000/studifrancesi.3175

Questo documento è stato generato automaticamente il 31 janvier 2023.

\section{(c) (i) (3)}

Creative Commons - Attribuzione - Non commerciale - Non opere derivate 4.0 Internazionale - CC BYNC-ND 4.0

https://creativecommons.org/licenses/by-nc-nd/4.0/ 


\title{
G. Fusco Girard, Mallarmé «Dernière Mode». L'infinito e il nulla
}

\author{
Michele Costagliola D'abele
}

\section{NOTIZIA}

G. FUSCO GIRARD, Mallarmé «Dernière Mode». L'infinito e il nulla, Fasano, Schena Editore, 2012 , pp. 192.

Giovannella Fusco Girard se livre à une lecture critique des rubriques des huit premières parutions de La Dernière Mode dont l'objectif fondamental est celui de réhabiliter l'expérience de journaliste de Mallarmé et de démontrer comment ce journal n'est pas un simple divertissement intellectuel mais représente le lieu choisi expressément par le poète pour véhiculer ses idées esthétiques et pour façonner sa poétique. Le journal en tant qu'«inquiétude, où le poète trouve l'écho de sa propre personnalité», un «reflet», un vide idéal où l'infini de la poésie trouve sa place fortunée, une flaque brève, pour utiliser une image chère à Yves Bonnefoy, où le mot poétique, infini comme le ciel, se reflète soudainement, tout entier. Le journal, malgré son but apparemment ludique, comme lieu où les mots «possèdent la capacité intrinsèque de se heurter entre eux», incitent à la réflexion et, loin de provoquer le «repos mental», n'aplanissent que le chemin vers l'universalité, vers l'infini.

2 Voilà que le journal devient le «point de départ», la genèse de la littérature qui «s'y décharge à souhait» puisqu'il représente «le premier mot, la première idée, l'origine». D'où l'attention maniaque de Mallarmé pour le mot, ce mot qui l'oblige à une «attention soufferte», ce mot qui cache un potentiel infini et qui, si dans le journal ne doit que «parer l'âme de la lectrice», il doit aussi se faire interprète de «l'univers dans le néant ou mieux de l'univers du néant». Il en résulte une phrase parfaitement construite qui, même quand elle décrit des sujets frivoles ayant trait à la mode, ne peut pas cacher le souci obsédant du poète, sa conviction que d'un seul mot, du premier mot, peut dériver, par suggestion et allusion, toute la gamme infinie des littératures possibles: «Je te jure 
qu'il n'y a pas un mot qui ne m'ait coûté plusieurs heures de recherche, et que le premier mot, qui revêt la première idée, outre qu'il tend lui-même à l'effet général du poème, sert encore à préparer le dernier», avouait Mallarmé lui-même.

3 C'est ainsi que Giovannella Fusco Girard nous propose de lire les rubriques de $L a$ Dernière Mode comme s'il s'agissait de véritables poèmes et nous invite à abandonner l'idée de rubrique en tant que simple bavarderie et à la considérer comme un dispositif pédagogique où Mallarmé «a disséminé des fragments de pensées et de réflexions»; la réalité, d'après elle, la réalité décrite dans un journal de mode, aussi splendide et captivante soit-elle, n'est que le point de départ de la recherche de l'invisible, de l'épars et l'indivisible - pour citer à nouveau Yves Bonnefoy - «cet aspect caché qui racontera de l'existence mieux que toute matérialité». Écrire un journal de mode, donc, a été pour Mallarmé l'occasion d'étudier la mode en tant qu'art, ce qui a requis d'adopter un point de vue éloigné de l'idée commune d'écriture et de lecture d'une revue ludique et de vulgarisation. Et, en même temps, étudier La Dernière Mode a représenté pour l'auteur de cet ouvrage l'occasion d'analyser une revue de mode comme une œuvre d'art. Elle a su y repérer, en dépit de l'apparente légèreté des sujets traités, «les failles du langage, jamais trop simple ni trop coulant, la structure phrastique non linéaire, l'enchevêtrement d'allusions philosophiques», des expédients rhétoriques qui se révèlent certes des véhicules d'information mais aussi de formation esthétique, les jalons d'un parcours esthétique transformé en «éducation morale» par Mallarmé luimême qui se sert de plusieurs noms de plume. Elle a su repérer y et souligner aussi les silences et en étudier la portée poétique, silences souvent plus expressifs que plusieurs mots, silences plus intenses et compréhensibles que les mots prononcés qui, eux, peuvent déranger la pensée de celui qui écrit et de celui qui lit. Il en résulte une idée de journal en tant qu'«incipit d'un long discours, d'une coulée de texte», le journal en tant que premier mot du Livre auquel Mallarmé a toujours aspiré.

4 Mais comme Giovannella Fusco Girard le souligne, pour que le Livre puisse se matérialiser, prendre forme, il n'est pas indispensable de l'écrire entièrement, une vie ne suffirait pas pour le faire: il suffit d'en montrer quelques aperçus, d'en suggérer quelques petits moments. Elle nous rend compte ainsi, avec cet ouvrage intéressant, d'un aspect particulier de la carrière de Mallarmé, d'une expérience qui l'a vu s'immerger «dans les plis infinis du temps, avec le temps et l'espace infinis qui attendent, même si rien ne sera jamais véritablement terminé». Face à tout cela, «la faible ténacité» des mots écrits dans un journal de mode, un journal qui s'est révélé un véritable «don de culture» tel Mallarmé «Dernière Mode». L'infinito e il nulla. 